\title{
Evaluation of Avocado Germplasm Using Microsatellite Markers
}

\author{
R.J. Schnell, J.S. Brown, C.T. Olano, E.J. Power, and C.A. Krol \\ National Germpasm Repository, U.S. Department of Agriculture, Agricultural Research Service, 13601 \\ Old Cutler Road, Miami, FL 33158 \\ D.N. Kuhn \\ Department of Biological Sciences, Florida International University, Miami, FL 33199 \\ J.C. Motamayor \\ Masterfoods Inc., U.S. Department of Agriculture, Agricultural Research Service, 13601 Old Cutler \\ Road, Miami, FL 33158
}

\begin{abstract}
AdDitional INDEX words. Persea americana, horticultural races, simple sequence repeat, molecular marker, genetic diversity, germplasm collection management

Abstract. Three horticultural races of avocado (Persea americana Mill.) are known: Guatemalan, Mexican, and West Indian. Each race has unique characteristics and current commercial varieties have been selected from within the races or from interracial hybrids. Using 14 microsatellite loci we investigated the genetic variation among 224 accessions (394 plants) maintained at the National Germplasm Repository (NGR) in Miami, Fla., and a set of 34 clones from the University of California South Coast Field Station (SCFS) located in Irvine, Calif. The 14 microsatellite loci had an average of 18.8 alleles per locus and average unbiased genetic diversity was 0.83 . The total propagation error in the collection, i.e., plants that had been incorrectly labeled or grafted, was estimated to be $7.0 \%$. Although many unique alleles did exist, no useful race-specific markers were found. A general concordance between the horticultural race and the clusters obtained from molecular data was observed. Principal Coordinate Analysis (PCA) grouped the Guatemalan and Mexican races into two distinct clusters. The West Indian also grouped into a unique major cluster but with an outlying group. Using the PCA a change in the racial designation or interracial hybrid status for 50 accessions (19.7\%) is proposed. The unbiased gene diversity estimate was highest in the Mexican and Guatemalan races and lower in the West Indian group. This demonstrates the need to collect more of the West Indian germplasm to broaden the genetic diversity and to emphasize the identification of individuals conferring resistance to Phytophthora Root Rot (PRR).
\end{abstract}

The avocado (Persea americana Mill.) is an evergreen subtropical tree that is native from Mexico to northern South America and produces a fruit that is unique and nutritious. This fruit was known by the Aztecs as ahuacacuauhitl, which was later shortened by the Spaniards to aguacate. In the United States avocado was introduced into Florida in 1833, California in 1848 and to Hawaii by 1855 (Nakasone and Paull, 1998). Major commercial production of avocado in the United States is limited to California and Florida. In 2000, global production exceeded 2.4 MMT and the major producers were Mexico, Indonesia, South Africa and the United States (Anonymous, 2001).

P. americana has been subdivided into three horticultural groups: Mexican [P. americana var. drymifolia (Schect. \& Cham.) Blake], Guatemalan (P. americana var. guatemalensis Wms.) and West Indian (P. americana var. americana Mill.) races. The West Indian race is known to be from the lowland areas of the Pacific coast of Central America and not the West Indies, while the Guatemalan and Mexican races are native to specific highland areas in each country (Scora and Bergh, 1992). The collection at the NGR-Miami contains 224 accessions with all three races represented, as well as hybrids between them. The earliest introductions were collected by Wilson Popenoe in Guatemala in the 1920s, and the newest introductions were collected by Avraham Ben-Ya'acov throughout Central and South America during the 1990s (Ben-Ya'acov, 1995; Popenoe,

Received for publication 19 Dec. 2002. Accepted for publication 11 July 2003. The authors thank R. Krueger, National Germplasm Repository for Citrus and Dates and D. Stottlemyer of the UC-Riverside for collecting and sending the avocado tissue from the South Coast Field Station.
1920). The University of California collection at the South Coast Field Station (SCFS) in Irvine contains a large number of accessions and breeding lines mostly of the Mexican and Guatemalan races and mixed interracial hybrids. These two collections contain a comprehensive representation of the genetic diversity currently in avocado germplasm collections.

The three racial groups can be distinguished by the percentage oil content in the fruit with the West Indian cultivars ranging from $2.5 \%$ to $8.0 \%$, Guatemalan accessions from $10 \%$ to $13 \%$, and the Mexican accessions ranging from $15 \%$ to $20 \%$ (Knight, 2002). The racial classes also vary phenotypically for characters such as fruit size and shape, skin thickness, skin color, seed size, and fruit ripening (Lahav and Lavi, 2002). Avocado is a diploid with $2 n=24$ (Garcia, 1975) and sterility barriers do not exist between or among the three racial types (Lahav and Lavi, 2002). Avocado has a distinct flowering habit known as protogynous, diurnally synchronous dichogamy (Bergh, 1969). This type of reproductive behavior promotes outcrossing; however, significant amounts of self-pollination are known to occur in commercial plantings (Davenport et al., 1994). Named cultivars often originate from open-pollinated seedlings. The pollen parent is unknown but has often been estimated based on the flower types of available donor trees. Many of the cultivars grown in Florida are interracial hybrids between Guatemalan and West Indian types while those grown in California are hybrids between Mexican and Guatemalan types (R. Knight, personal communication). Morphological characters have been used to infer parentage, although these characters are influenced by environmental factors and may not unambiguously distinguish closely related genotypes or interracial hybrids. 



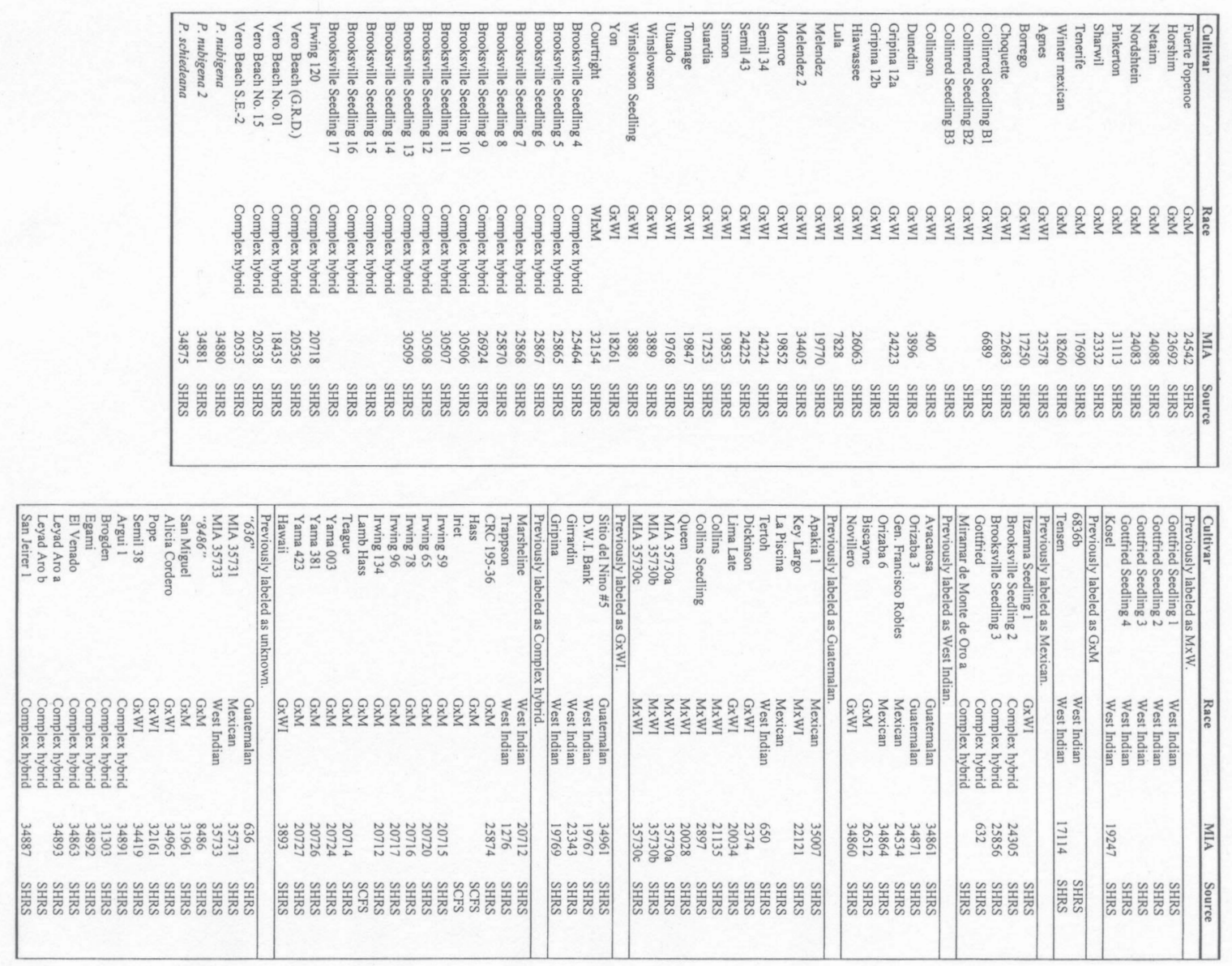
Molecular markers are often used to clarify genetic relationships between individuals. In avocado germplasm evaluated using minisatellite markers, racial pattern differences were observed and fingerprinting of 26 cultivars was accomplished (Lavi et al., 1991). Mhameed et al. (1997) used variable number of tandem repeats (VNTR) markers to evaluate genetic relationships among 24 avocado cultivars that had been classified using morphological traits. The VNTR data supported the racial classification for most of the accessions. In another study, RAPD markers were used to evaluate 16 accessions representing the three races. Race-specific markers were identified and the similarity between races ranged from 53\% to 58\% (Fiedler et al., 1998). Similarly, Davis et al. (1998) used Restriction Fragment Length Polymorphism (RFLP) to evaluate a set of 36 cultivars from the University of California SCFS and their results were in agreement with the previous studies.

Microsatellite markers have been developed for avocado and utilized to produce a crude linkage map (Sharon et al., 1997). These markers have distinct advantages over the other types of molecular markers used to classify avocado germplasm. Their advantages include their abundance in most genomes, uniform distribution, hypervariability, codominance, and PCR-based protocols. Even though the genetic diversity analysis from the aforementioned studies sampled a small number of accessions, they have adequately demonstrated the usefulness of molecular markers in the classification of avocado germplasm.

Our objectives were to estimate genetic diversity within the large collection maintained at the USDA, NGR in Miami and a subset of the collection maintained at the SCFS by the University of California using microsatellite markers. Genetic diversity within and between populations of avocado was of interest, particularly within the West Indian race that is known to have genes involved with tolerance to phytophthora root rot (PRR). Another objective was to clarify the anecdotal information on parentage of mixed race hybrids and seedling selections from commercial cultivars. Since all plants (clones) of a given accession were genotyped, we also investigated the fidelity of germplasm propagation within accessions, as clonal collections are known to contain identical accessions with different names and mixtures of genotypes with the same name (Schnell et al., 1999).

\section{Materials and Methods}

Plant materials. Leaf material was sampled from the Persea germplasm collection at the NGR in Miami, Fla., and from the SCFS, University of California, Irvine, Calif. The number of plants genotyped for this study was 428 . This included 254 accessions, 224 from the NGR-Miami and 34 from the University of California SCFS at Irvine with four cultivars common to both collections. Of the 224 accessions at the NGR, 104 accessions were represented by multiple plants. These 274 plants include 54 accessions with two, 37 accessions with three, 10 accessions with four, and three accessions with five plants.

In total, individuals of the following backgrounds were studied: 51 Mexican, 35 Guatemalan, and 65 West Indian, 100 interracial hybrids, and three related species. Hybrids were designated as follows: Complex $(\mathrm{CH})$, Guatemalan $x$ West Indian $(\mathrm{G} \times \mathrm{W})$, Guatemalan x Mexican ( $\mathrm{G} \times \mathrm{M})$, and Mexican $\times$ West Indian ( $\mathrm{M}$ x W). The out-group consisted of two accessions of $P$. nubigena and one accession of $P$. schiedeana (Table 1).

Table 2. Microsatellite loci and primers used in the analysis of the avocado germplasm collections developed by Sharon et al. (1997).

\begin{tabular}{|c|c|c|c|c|c|c|}
\hline Locus & Repeat & Primers (5'-3') & $\begin{array}{c}\text { Annealing } \\
\text { temp } \\
\left({ }^{\circ} \mathrm{C}\right)\end{array}$ & $\begin{array}{c}\text { Alleles } \\
\text { (no.) }\end{array}$ & $\begin{array}{c}\text { Size } \\
\text { range } \\
\text { (bp) }\end{array}$ & $\begin{array}{c}\text { Diversity } \\
{[\hat{\mathrm{H}} \pm \mathrm{V}(\hat{\mathrm{H}})]}\end{array}$ \\
\hline \multirow[t]{2}{*}{ AVAG05 } & $(\mathrm{AG})_{10}$ & GGATCTTGATGTGTGGGGGAG & & & & \\
\hline & & CCTGTCGGAAAAGACTATGCG & 50 & 19 & $83-125$ & $0.7906(0.0394)$ \\
\hline \multirow[t]{2}{*}{ AVAG03 } & $(\mathrm{TC})_{17}$ & GCACTTCCTAAACTTGCAGGT & & & & \\
\hline & & CTGAACATCCAATGACAAACATCC & 45 & 14 & $92-122$ & $0.8414(0.0551)$ \\
\hline \multirow[t]{2}{*}{ AVAG25 } & $(\mathrm{TC})_{14}$ & ATGGTTTTTTCCTGCCCTTT & & & & \\
\hline & & AACAAGCCCCCTAAAAGAA & 50 & 20 & $96-140$ & $0.8640(0.0596)$ \\
\hline \multirow[t]{2}{*}{ AVAG13 } & $(\mathrm{CT})_{18}$ & CTGCGATAACAACTGGAC & & & & \\
\hline & & AACTAGGACCTGAAACCG & 50 & 29 & $96-160$ & $0.9150(0.0912)$ \\
\hline \multirow{2}{*}{ AVAG11 } & $(\mathrm{AG})_{20}$ & AGCGATGAACATTACCA & & & & \\
\hline & & АTTTCTTCAACCCATCTGTC & 50 & 15 & $105-161$ & $0.7553(0.0388)$ \\
\hline \multirow[t]{2}{*}{ AVMIX03 } & $(\mathrm{TG})_{16},(\mathrm{AG})_{20}$ & GATATTCCTGTTGTCACTGC & & & & \\
\hline & & GATATTCCTGTTGTCACTGC & 50 & 23 & 139-196 & $0.8912(0.0718)$ \\
\hline \multirow[t]{2}{*}{ AVAG21 } & $(\mathrm{CT})_{22}$ & TGTAAGTTTTAACCCCACAA & & & & \\
\hline & & AATCACTATTAGAGTTTTCAGTCG & 50 & 30 & $153-219$ & $0.8911(0.0729)$ \\
\hline \multirow[t]{2}{*}{ AVAG07 } & $(\mathrm{TC})_{15}$ & ATCCAAAATGCACAAGGTGAGG & & & & \\
\hline & & TGTCGCTATGTCCAAAATGTGG & 50 & 8 & $98-114$ & $0.6524(0.2801)$ \\
\hline \multirow[t]{2}{*}{ AVMIX04 } & $(\mathrm{AG})_{12},(\mathrm{CAA})_{5},(\mathrm{ACAG})_{10}$ & CCGTTTGCTTCCTGTATC & & & & \\
\hline & & GTTATCCCTTCCACTTTC & 50 & 19 & 158-194 & $0.8922(0.0750)$ \\
\hline \multirow[t]{2}{*}{ AVAC01 } & $(\mathrm{TG})_{15}$ & CTGGTTGCTCTCTTGTCTACATAATA & & & & \\
\hline & & CGGTTTTGTAAGTTGATAG & 40 & 16 & $95-185$ & $0.8627(0.0597)$ \\
\hline \multirow[t]{2}{*}{ AVMIX02 } & $(\mathrm{TC})_{6},(\mathrm{TCC})_{4}$ & GAGTCACGCTCGTAGGCT & & & & \\
\hline & & TATAAATTCAAATGACAC & 40 & 10 & $147-135$ & $0.7335(0.0363)$ \\
\hline \multirow[t]{2}{*}{ AVAG06 } & $(\mathrm{CT})_{18}$ & CGACCTCTTCTTATACTC & & & & \\
\hline & & GTACCTCTGATAATGAGCAT & 40 & 15 & $59-89$ & $0.8625(0.0629)$ \\
\hline \multirow[t]{2}{*}{ AVAG10 } & $(\mathrm{CT})_{22}$ & GAATTACAAAGCACTAGAG & & & & \\
\hline & & GTAGAAAGTGGGCACACAT & 45 & 30 & 149-234 & $0.8695(0.0607)$ \\
\hline \multirow[t]{2}{*}{ AVAG22 } & $(\mathrm{GA})_{15}$ & GATCATCAAGTCCTCCTTGG & & & & \\
\hline & & GATCTCATAGTCCAAATAATGC & 55 & 16 & $96-130$ & $0.8206(0.0597)$ \\
\hline
\end{tabular}


DNAextraction was performed on $200 \mathrm{mg}$ samples of leaf tissue using the Fast DNA kit (BIO 101, Inc.; Carlsbad, Calif.) and a cell disrupter (FastPrep FP 120; Savant Instruments, Inc.; Holbrook, N.Y.). The kit protocol for plant tissue was followed including the optional SPIN protocol. Tissue was homogenized using the Garnet Matrix and two $1 / 4$-inch spheres as the Lysing Matrix combination, at speed 5 for $30 \mathrm{~s}$, repeated three times. DNA was quantified on a spectrophotometer (DynaQuant 200; Amersham Pharmacia; Piscataway, Calif.)

Microsatellite Markers and PCR amplification. The microsatellite markers used in this study were reported by Sharon et al. (1997). Initially, 39 primer pairs were tested of which 14 were selected based on amplification consistency and level of polymorphism. Microsatellite locus name and primer sequence are listed in Table 2. PCR amplification reactions were carried out in a total volume of $10 \mu \mathrm{L}$, or $20 \mu \mathrm{L}$ for multiplex reactions, containing 0.25 ng $\mu \mathrm{L}^{-1}$ genomic DNA. All PCR reactions contained $0.025 \mathrm{U} / \mu \mathrm{L}$ Amplitaq (Applied Biosystems, Inc.; Foster City, Calif.), $0.2 \mathrm{~mm}$ dNTPs, $0.25 \mu \mathrm{m}$ each forward and reverse primers, $1 \times$ GeneAmp PCR buffer (1.5 mм $\mathrm{MgCl}_{2}, 10$ mм Tris-HCl pH8.3, 50 mм KCl, $0.001 \%(\mathrm{w} / \mathrm{v})$ gelatin). Thermal cycling profile consisted of the following: 4 min denaturation at $94{ }^{\circ} \mathrm{C}$; followed by 33 cycles of denaturation at $94{ }^{\circ} \mathrm{C}$ for $30 \mathrm{~s}, 1 \mathrm{~min}$ at appropriate annealing temperature for each primer (Table 2), 1 min extension at $72{ }^{\circ} \mathrm{C}$; with a final 7 min $72{ }^{\circ} \mathrm{C}$ extension. PCR was carried out on a DNA Engine tetrad thermal cycler(MJ Research, Inc.; Watertown, Mass.). The following PCR multiplex reaction combinations were used: AVAG11 and AVMIX03, AVAG21 and AVAG07, and AVMIX02 and AVAG06, all other primer pairs were run individually.

ELECTROPHORESIS. Capillary electrophoresis (CE) was performed on an genetic analyzer (ABI Prism 3100; Applied Biosystems, Inc.) using Performance Optimized Polymer 4 (POP 4, Applied Biosystems, Inc.). Samples were prepared immediately before electrophoresis by adding $1 \mu \mathrm{L}$ of PCR product to $12 \mu \mathrm{L}$ of deionized formamide and $0.1 \mu \mathrm{L}$ of GeneScan 500 ROX size standard (Applied Biosystems, Inc.), then denatured at $95^{\circ} \mathrm{C}$ for 5 min, and chilled on ice. PCR products and size standards were doubled for preparation of multiplex PCR amplifications. Samples were injected electrokinetically at $3 \mathrm{kV}$ for $10 \mathrm{~s}$ and were run at $15 \mathrm{kV}$ and $60{ }^{\circ} \mathrm{C}$ for $25 \mathrm{~min}$. Resulting data were analyzed with GeneScan 3.7 (Applied Biosystems, Inc.) for internal standard and fragment size determination. Allelic designations were ascertained using Genotyper 3.7 (Applied Biosystems, Inc.).

Data ANaLYSIS. Gene diversity values for each locus and averages across all loci for the three races and interracial groups were calculated using Nei's (1987) unbiased estimate $\hat{H}=n\left(1-\sum p_{i}^{2} / n\right.$ -1 , where $\mathrm{n}=$ number of individuals sampled, $p_{\mathrm{i}}$ is the frequency of the $i$ th allele. The variance of this statistic was calculated as $V(\hat{H})=2 /\left[(\mathrm{n}-2)\left[\sum p^{3}{ }_{i}-\left(\sum p_{i}\right)^{2}\right]+\sum p^{2}{ }_{i}-\left(\sum p_{i}{ }^{2}\right)^{2}\right]$.

Unbiased gene diversity $\left(\mathrm{H}_{\mathrm{nb}}\right)$ and observed heterozygosity $\left(\mathrm{H}_{\mathrm{obs}}\right)$ were estimated from the allele frequencies of the Guatemalan, Mexican, and West Indian populations as well as $\mathrm{CH}, \mathrm{G} \mathrm{x}$ $\mathrm{M}, \mathrm{G} \times \mathrm{W}, \mathrm{M} \times \mathrm{W}$, and the Persea spp. group, at each locus using GENETIX ver. 4.0 (Montpellier, France).

The principal coordinate analyses (PCA; Sokal and Rohlf, 1998) were performed on subsets of the data using the SAS System for Windows ver. 8.0 (SAS Institute; Cary, N.C.) with modified Rogers' distance (Wright, 1978). Due to the number of taxa and resulting difficulty in visualizing individuals in the 3-D PCA, the Guatemalan, Mexican, and West Indian populations were analyzed together first. This was followed by the analysis of the other interracial hybrid groups, one at a time, to determine where they clustered in relation to the three primary populations.

The relationships between the populations were also represented using a phenetic tree constructed from allele frequencies averaged over populations, using the Cavalli-Sforza and Edwards (1967) chord distance and the neighbor joining method (NJ; Saitou and Nei, 1987). Statistical analysis was accomplished by testing for similarities in allele frequencies using genotypic counts between groups as suggested by Weir (1996). Chi-square analysis of the contingency tables was generated using the Proc. Freq procedure with Monte Carlo simulation for estimates of exact $P$ values and 1000 iterations. The Monte Carlo option was used due to the size of the data set and the computational resources required by the analysis (SAS, 1999).

\section{Results}

LEVEL OF POLYMORPHISM. The 14 microsatellite loci were highly polymorphic. The number of alleles varied from eight (AVAG07) to 30 (AVAG21), with an average of 18.8 alleles per locus and the average gene diversity was 0.83 ( 0.65 to 0.91 ) (Table 2 ). Eleven of the 14 microsatellites were composed of simple dinucleotide repeat motifs. Seven of these gave amplification products differing by either two bases or multiples of two for each allele. An example of the allelic diversity is given in Fig. 1 for locus AVAG06 showing 8 of the 15 alleles detected at this locus in eight accessions including P. nubigena. AVAG13 had two of 29 alleles that were not multimers of the repeat unit, while AVAG21 contained nine of 30 alleles that differed by a single base. Additionally, AVAG10 and AVAG11 generated two of 29 and three of 15 alleles, respectively, that were not multimers of the repeat unit. Two of the three microsatellite

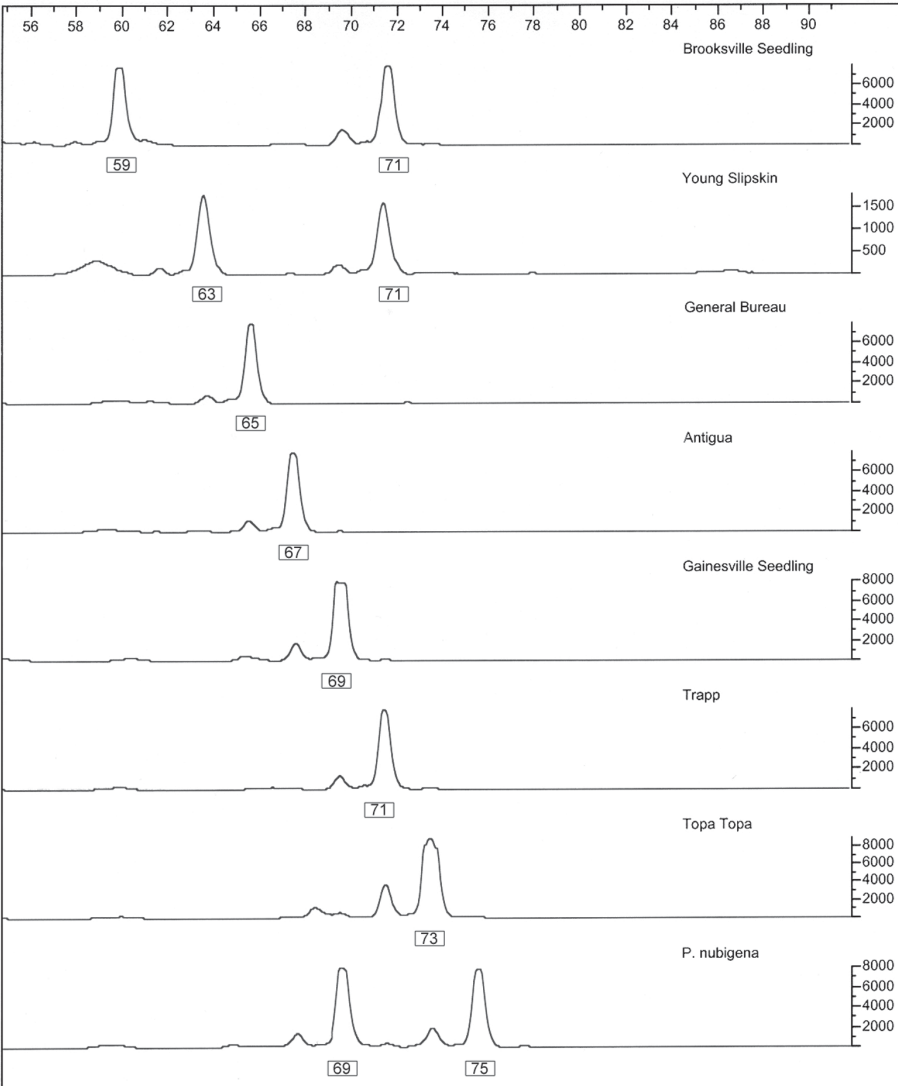

Fig. 1. Allele sizes in base pairs detected at the AVAG-06 microstatellite locus in eight Persea accessions illustrating eight alleles using the computer program Genotyper ver 4.0. The major peak in each electropherogram is the PCR amplified allele at this locus. 
Table 3. Allele size for each locus and comparison of Ettinger and Pinkerton for allele sizes at the 14 microsatellite loci.

\begin{tabular}{|c|c|c|c|c|c|c|c|c|c|c|c|c|c|c|}
\hline Allele & AVAG05 & AVAG03 & AVAG25 & AVAG13 & AVAG11 & AVMIX03 & AVAG21 & AVAG07 & AVMIX04 & AVACO1 & AVMIX02 & AVAG06 & AVAG10 & AVAG22 \\
\hline$T$ & 83 & 92 & 96 & 96 & 105 & 139 & 153 & --- & 158 & 95 & 147 & 59 & 149 & 96 \\
\hline 2 & 85 & 94 & 98 & 98 & 107 & 141 & 167 & 98 & 160 & 99 & 149 & 63 & 174 & 98 \\
\hline 3 & 87 & 96 & 100 & 100 & 109 & 143 & 171 & 100 & 162 & 103 & 153 & 65 & 176 & 100 \\
\hline 4 & 89 & 98 & 102 & 102 & 113 & 145 & 173 & 102 & 164 & 105 & 155 & 67 & 178 & 102 \\
\hline 5 & 91 & 100 & 104 & 104 & 115 & 147 & 175 & 104 & 166 & 107 & 157 & 69 & 180 & 104 \\
\hline 6 & 93 & 102 & 106 & 106 & 116 & 151 & 177 & 106 & 168 & 109 & 159 & 71 & 182 & 106 \\
\hline 7 & 95 & 104 & 108 & 108 & 118 & 152 & 179 & 108 & 170 & 111 & 163 & 73 & 184 & 108 \\
\hline 8 & 97 & 106 & 110 & 110 & 125 & 154 & 180 & 112 & 172 & 113 & 165 & 75 & 185 & 110 \\
\hline 9 & 99 & 108 & 112 & 112 & 129 & 156 & 181 & 114 & 174 & 115 & 167 & 77 & 186 & 112 \\
\hline 10 & 101 & 110 & 114 & 114 & 131 & 158 & 183 & & 176 & 117 & 185 & 79 & 187 & 114 \\
\hline 11 & 103 & 112 & 118 & 116 & 132 & 160 & 186 & & 178 & 119 & & 81 & 188 & 116 \\
\hline 12 & 105 & 114 & 120 & 118 & 133 & 162 & 187 & & 180 & 121 & & 83 & 190 & 118 \\
\hline 13 & 107 & 116 & 122 & 120 & 137 & 164 & 188 & & 182 & 123 & & 85 & 192 & 120 \\
\hline 14 & 109 & 122 & 124 & 122 & 147 & 166 & 189 & & 184 & 127 & & 87 & 194 & 122 \\
\hline 15 & 111 & & 128 & 126 & 161 & 168 & 190 & & 186 & 131 & & 89 & 196 & 124 \\
\hline 16 & 113 & & 130 & 128 & & 170 & 191 & & 188 & 135 & & & 298 & 130 \\
\hline 17 & 119 & & 134 & 130 & & 172 & 193 & & 190 & & & & 200 & \\
\hline 18 & 121 & & 136 & 132 & & 174 & 194 & & 192 & & & & 202 & \\
\hline 19 & 125 & & 138 & 134 & & 178 & 195 & & 194 & & & & 204 & \\
\hline 20 & & & 140 & 136 & & 182 & 196 & & & & & & 206 & \\
\hline 21 & & & & 138 & & 190 & 198 & & & & & & 208 & \\
\hline 22 & & & & 141 & & 192 & 199 & & & & & & 210 & \\
\hline 23 & & & & 143 & & 196 & 201 & & & & & & 216 & \\
\hline 24 & & & & 146 & & & 202 & & & & & & 218 & \\
\hline 25 & & & & 148 & & & 203 & & & & & & 220 & \\
\hline 26 & & & & 152 & & & 204 & & & & & & 222 & \\
\hline 27 & & & & 154 & & & 207 & & & & & & 224 & \\
\hline 28 & & & & 158 & & & 209 & & & & & & 228 & \\
\hline 29 & & & & 160 & & & 215 & & & & & & 230 & \\
\hline 30 & & & & & & & 219 & & & & & & 234 & \\
\hline \multicolumn{15}{|c|}{ Allele size } \\
\hline \multicolumn{15}{|c|}{ Ettinger(Akko Expt. Station) } \\
\hline & 95/99 & 96 & 100 & $134 / 140$ & 109/115 & $146 / 147$ & $172 / 184$ & $108 / 120$ & $164 / 170$ & 113/117 & $153 / 171$ & $81 / 87$ & 153 & 103/117 \\
\hline \multicolumn{15}{|c|}{ Ettinger (NGR-Miami) } \\
\hline & $87 / 95$ & 94 & 102 & $122 / 128$ & $109 / 161$ & $143 / 172$ & $167 / 190$ & $100 / 112$ & $162 / 170$ & $109 / 113$ & $157 / 167$ & $77 / 83$ & 190 & $100 / 114$ \\
\hline \multicolumn{15}{|c|}{ Pinkerton(Akko Exp. Station) } \\
\hline & $95 / 99$ & $98 / 106$ & $106 / 110$ & 130 & 107 & $146 / 170$ & $192 / 200$ & $110 / 113$ & 180 & 117 & $153 / 171$ & $77 / 85$ & $149 / 153$ & 117 \\
\hline \multicolumn{15}{|c|}{ Pinkerton (NGR-Miami) } \\
\hline & $89 / 91$ & $96 / 102$ & $104 / 106$ & 118 & 107 & $143 / 166$ & $181 / 198$ & $102 / 106$ & 180 & $\mathrm{NA}^{\mathrm{z}}$ & $149 / 167$ & $69 / 81$ & $149 / 186$ & 114 \\
\hline
\end{tabular}

${ }^{2} \mathrm{NA}=$ no amplification.

loci that contained mixed repeat motifs gave amplification products differing by two bases or multiples of two for each allele.

ACCESSion IDENTIFiCATion. Of the 104 accessions with duplicate plants, $85(82 \%)$ had identical allelic configurations over all loci. Nonidentical allelic configurations usually resulted when one of three or four trees was not the same genotype. Many of these off-type plants had been previously detected based on phenotypic differences and the molecular data confirmed the misidentification. The 104 duplicated accessions are represented by 274 plants, only 19 of which were genotypically different from their sibling clones. The rate of error associated with propagation of the avocado collection is estimated to be $7.0 \%$. Of the four cultivars common to both the NGR and SCFS, three were identical between collections, 'Bacon', 'Ettinger', and 'Mexicola'. 'Nimlioh' differed at 12 of the 14 loci. The cultivars 'Ettinger' and 'Pinkerton' were used in the study by Sharon et al. (1997) where the microsatellite markers were developed. These two cultivars were also included in our study. The comparison of allele sizes for 'Pinkerton' produced very similar fragment sizes, ours being on average 4.5 bp smaller, with the exception of alleles at two loci. For locus AVAG10 Sharon et al. (1997) reported allele sizes of 149 and $153 \mathrm{bp}$, whereas our alleles are 149 and $190 \mathrm{bp}$. Another difference occurred at locus AVACO1 where we obtained no amplification products, whereas Sharon et al. (1997) reported one amplification product at $117 \mathrm{bp}$. The comparison of allele sizes for 'Ettinger' also produced very similar fragment sizes, ours being on average 4.8 bp smaller, with the exception of alleles at six loci that were on average $20 \mathrm{bp}$ larger. For example, the largest difference occurred at locus AVAG11 where Sharon et al. (1997) reported allele sizes of $109 \mathrm{bp}$ and $115 \mathrm{bp}$, whereas our amplification products were $109 \mathrm{bp}$ and $161 \mathrm{bp}$ (Table 3).

GENETIC DIFFERENTIATION BETWEEN HORTICULTURAL RACES AND RELATEDNESS OF CULTIVARS. The PCA supports the grouping for the West Indian, Guatemalan, and Mexican races as illustrated in Fig. $2 \mathrm{~A}$ where only the individuals within each race were analyzed. The PCA was able to summarize $29.7 \%$ of the total variability onto the three axes shown in this plot $(18.3 \%, 6.4 \%$, and $5.0 \%$, respectively, for Prin1, Prin2, and Prin3). The PCA based on gene frequency suggested that the race of some accessions was incorrectly assigned. Six of the West Indian accessions did not group with the West Indian cluster. Two of these six, 'General Francisco Robles' and 'Orizaba 6' are clearly Mexican; both contained estragole in their leaves. Two others, 'Avocatosa' and 'Orizaba 3' clustered with the Guatemalan group while 'Biscayne' is most likely a M x W hybrid and 'Novillero' is most likely a G x M hybrid. Based on the PCA, 12 of the Guatemalan accessions clustered in problematic areas. 'Tehtoh' is clearly a West Indian accession, 'La Piscina' is Mexican and nine of the other accessions are mixed racial hybrids, 'Collins Seedling 2', 'Collins', 'MIA35730a', 'MIA35730b', 'MIA35730c', and 'Key Largo' all are M x W hybrids while 'Dickinson' and 'Lima Late' are G x W hybrids. 'PIC9651' clustered in the Mexican accessions; however it was listed as a Guatemalan accession (Ben-Ya'acov, 1995) and does not contain estragole in the leaves. Based on the PCA, five of the Mexican accessions clustered in problematic areas. 'Brooksville Seedling 2' and 'Brooksville Seedling 3' seem to be West Indian or West Indians hybrids while 'Gottfried' and 'Miramar de Monte de Oro' seem to be CH. 'Itzamna Seedling 1 ' clustered as a $\mathrm{G} \times \mathrm{W}$. These changes are illustrated in Fig. 2A where the original racial designations are indicated with different symbols and the putatively misidentified accessions are labeled. In 


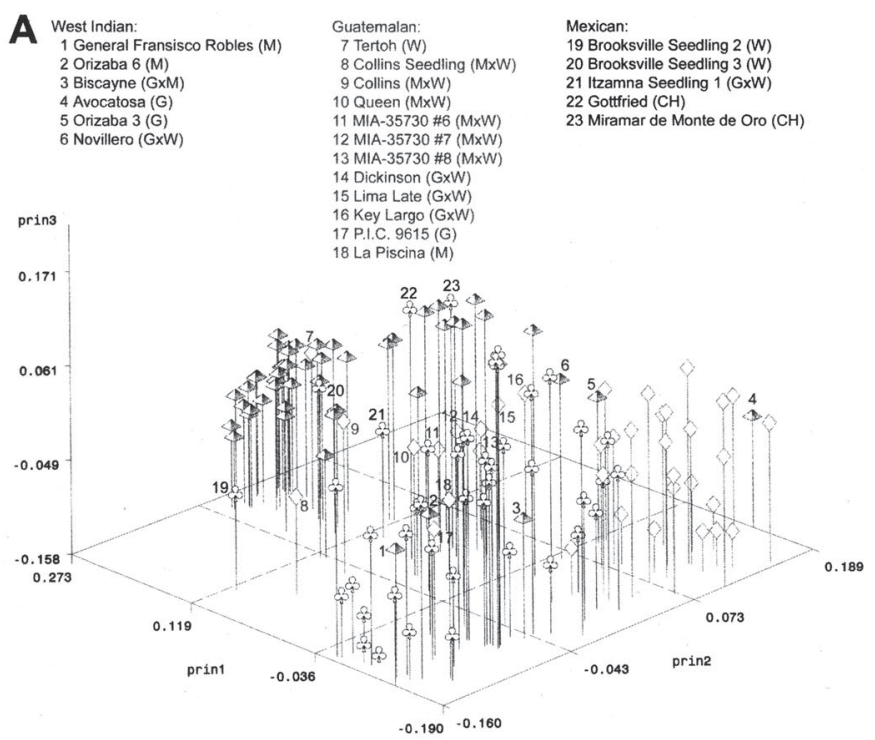

19 Brooksville Seedling 2 (W)
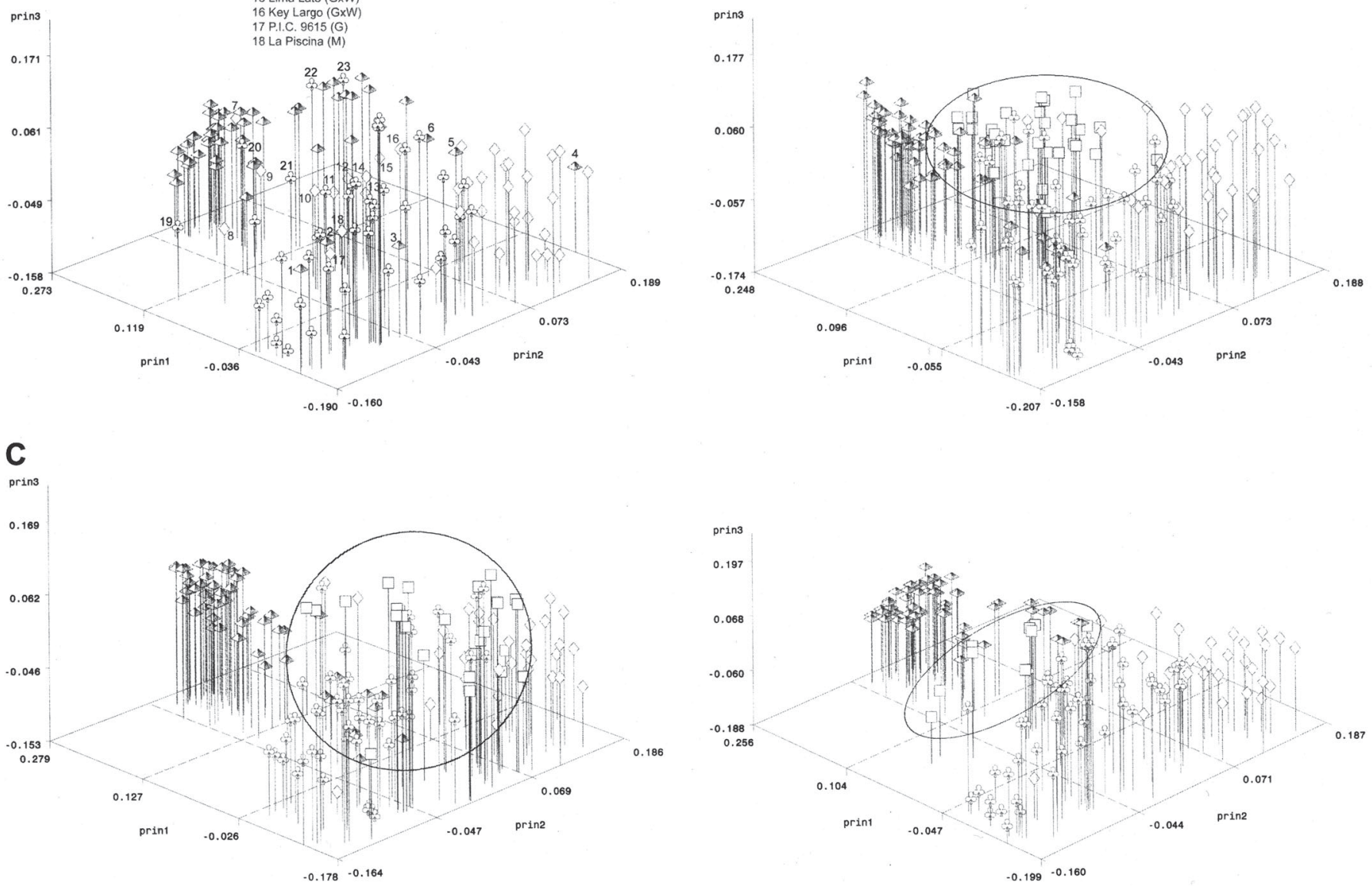

Fig. 2. Principal coordinate analysis (PCA) for the microsatellite evaluation of the avocado germplasm. Guatemalan accessions, $\bullet$ Mexican accessions, $\Delta$ West Indian accessions. (A) PCA for the Guatemalan, Mexican, and West Indian avocado accessions based on 14 microsatellite loci and illustrating incorrect population classification within each racial group, correct classification in parenthesis. This plot contains $29.7 \%$ of the total variability, $18.3 \%$ for the first principal coordinate axis, $6.4 \%$ for the second, and $5.0 \%$ for the third. Symbols $(\boldsymbol{*}, \Delta)$ indicate original classification. (B) PCA for the Guatemalan, Mexican, West Indian races, and the G x W hybrids. Plot contains $27.9 \%$ of the total variability, $17.4 \%$ for the first principal coordinate axis, $5.9 \%$ for the second, and $4.6 \%$ for the third; $\square=$ G x W. (C) PCA for the Guatemalan, Mexican, West Indian races, and the GxM hybrids. Plot contains 29.5\% of the total variability, 20.1\% for the first principal coordinate axis, 5.1\% for the second, and 3.9\% for the third; $\square=G \times$ M. (D) PCA for the Guatemalan, Mexican, West Indian races, and the MxW hybrids. Plot contains $29.9 \%$ of the total variability, $20.4 \%$ for the first principal coordinate axis, $5.0 \%$ for the second, and $4.0 \%$ for the third; $\square=\mathrm{M} \times \mathrm{W}$.

a similar manner, the other interracial hybrid groups were analyzed and changes made based on the PCA. All of the Unknown accessions (15) could be placed in racial or hybrid groups so they were no longer considered as a group for analysis purposes. A total of 50 accessions (19.7\%) were changed based on the PCA and these changes are listed in Table 1. All further analysis, including PCA and phylogenetic, was done using this corrected dataset.

PCAfor the Guatemalan, Mexican, and West Indian populations and the three interracial groups are illustrated in Fig. 2B-D. The PCA that includes the G $\times$ W hybrid grouping accounted for $28 \%$ of the total variation and the $\mathrm{G} \times \mathrm{W}$ accessions clustered between the two source populations (Fig. 2B). Likewise, Fig. 2C illustrates the $\mathrm{G} \times \mathrm{M}$ accessions clustering between the two source populations and the PCA accounts for $29.5 \%$ of the total variation. Fig. 2D illustrates the $\mathrm{M} \times \mathrm{W}$ accessions again clustering between the two source populations with the PCA accounting for $29.9 \%$ of the variation. The PCA for the $\mathrm{CH}$ group is not illustrated but these cluster together in a different area that overlaps with the other interracial hybrids.

Significant differences were found for each racial comparison, Guatemalan vs. West Indian, Guatemalan vs. Mexican, and Mexican vs. West Indian for 13 of the 14 loci from the Chi-square analysis. Significant frequency differences were also detected for locus AVAG22 between the Guatemalan vs. West Indian and

Table 4. Chi-square values for tests of similarity of allele frequency by racial background. ${ }^{2}$

\begin{tabular}{|c|c|c|c|c|c|c|c|c|c|c|c|c|c|c|}
\hline Locus & AVAG05 & AVAG03 & AVAG25 & AVAG13 & AVAG11 & AVMIX03 & AVAG21 & AVAG07 & AVMIX04 & AVACO1 & AVMIX02 & AVAG06 & AVAG10 & AVAG22 \\
\hline$\overline{\text { G vs. W }}$ & $135.83^{* *}$ & $84.05^{* * *}$ & $83.14^{* *}$ & $141.18^{* * *}$ & $97.45^{* *}$ & $114.82^{* * *}$ & $98.33^{* *}$ & $76.20^{* *}$ & $94.09^{* *}$ & $105.42^{* *}$ & $151.85^{* *}$ & $100.66^{* *}$ & $123.13^{* *}$ & $20.75^{*}$ \\
\hline G vs. M & $70.17^{* *}$ & $29.12^{* *}$ & $32.71^{* *}$ & $68.74^{* *}$ & $50.34^{* *}$ & $68.83^{* *}$ & $68.28^{* *}$ & $44.15^{* *}$ & $81.69^{* *}$ & $44.98^{* *}$ & $68.24^{* *}$ & $45.36^{* *}$ & $67.34^{* *}$ & 14.42 \\
\hline M vs. W & $133.65^{* *}$ & $112.53^{* *}$ & $120.11^{* *}$ & $156.22^{* *}$ & $150.15^{* *}$ & $144.40^{* *}$ & $149.90^{* *}$ & $108.77^{* *}$ & $155.91^{* *}$ & $78.72^{* *}$ & $183.45^{* *}$ & $144.69^{* *}$ & $140.98^{* *}$ & $21.47^{*}$ \\
\hline
\end{tabular}

${ }^{2} \mathrm{G}=$ Guatemalan, $\mathrm{M}=$ Mexican, and $\mathrm{W}=$ West Indian races.

**** Signifiant at $P<0.05$ or 0.01 , respectively. 


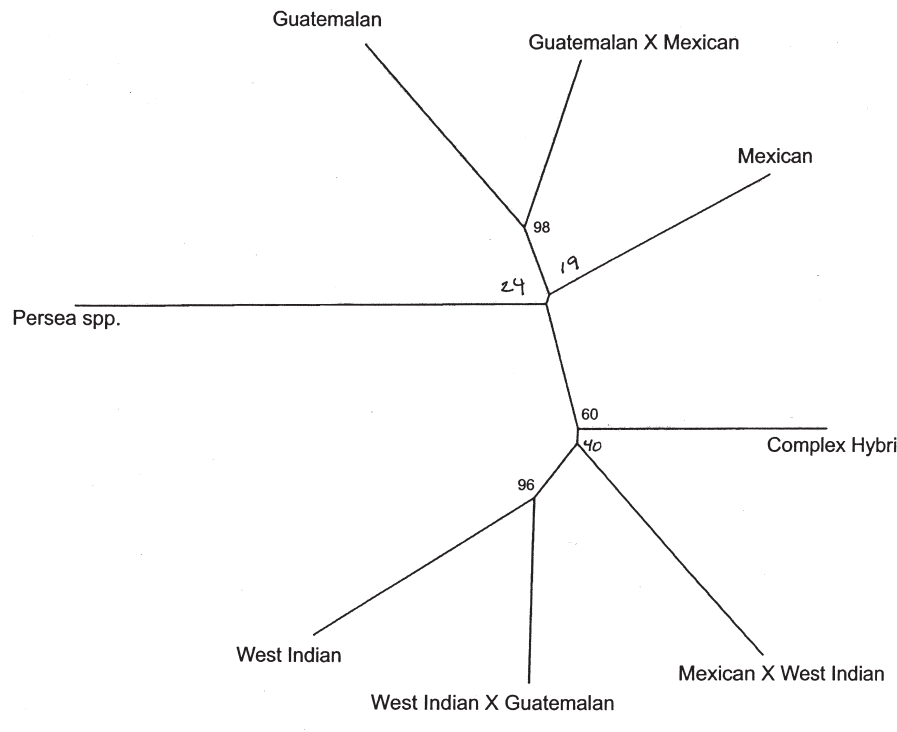

Fig. 3. Neighbor-joining tree of Guatemalan, Mexican, and West Indian races and interracial hybrids based on the Cavalli-Sforza and Edwards chord distance calculated from microsatellite data. Bootstrap percentages were computed using 1000 replications. Bootstrap values below $50 \%$ are not shown.

Mexican vs. West Indian but not for the Guatemalan vs. Mexican comparison (Table 4).

Phylogenetic analysis of the microsatellite data for the three populations and the inter-population hybrids was in agreement with the previously reported genetic relationships that separated the Guatemalan, Mexican and West Indian races (Davis et al., 1998; Fiedler et al., 1998; Mhameed et al., 1997). The NJ tree based on Cavalli-Sforza and Edwards (1967) chord distance grouped the three races into distinct clusters. The Persea spp. were distinct from any other group. The Guatemalan race and $\mathrm{G} \times \mathrm{M}$ hybrids clustered together with a high bootstrap value and the West Indian and $\mathrm{W} \times \mathrm{G}$ clustered together again with a high bootstrap value, all other groups had little bootstrap support (Fig. 3).

All of the groups had a high average allele number, with the exception of the $\mathrm{M} \times \mathrm{W}$ group that only contained eight individuals ( 3.57 to 13.35 , Table 5 ). All loci were polymorphic when considered over all groups. $\mathrm{H}_{\mathrm{nb}}$ was high in the Mexican (0.83) and Guatemalan populations (0.81) and lower for the West Indian group $(0.61)$. The other groups had a narrow range 0.79 to $0.75 . \mathrm{H}_{\text {obs }}$ did not follow the same pattern being higher in the Guatemalan population (0.75), lower in the Mexican (0.66) and lower still in the West Indian (0.50). The M x W, G x W hybrids and $\mathrm{CH}$ had a high $\mathrm{H}_{\text {obs }}, 0.87,0.79$ and 0.78 respectively, while the Persea spp. and $\mathrm{G} \times \mathrm{M}$ were similar, 0.70 (Table 5).

With the exception of the $\mathrm{M} \times \mathrm{W}$ hybrids, all other racial groupings contained unique alleles, 27 among the Mexican accessions, 16 in the West Indian group, seven among the Guatemalan accessions, and from one to four among the other groups (data not shown). Of these unique alleles, only three were at a frequency greater than 0.05. Two of these were found in both of the Persea spp. accessions ( 0.33 and 0.75 due to the existence of a null allele in P. schiedeana) and the other in the $\mathrm{CH}$ group (0.13). Only one allele in the Guatemalan population had a frequency greater than 0.50, allele 9 for locus AVMIX02 with a frequency of 0.71 . Both the Mexican and West Indian populations contained this allele but at low frequencies of 0.17 and 0.04 , respectively. The highest frequency in the Mexican population was 0.44 at locus AVAG11 for allele 2 and 0.46 at locus AVMIX02 for allele 2. The West Indian population had alleles with frequencies greater than 0.50 for eight of the loci, AVAG05 allele $6(0.75)$, AVAG03 allele 6 (0.53), AVAG11 allele 2 (0.72), AVAG07 allele 3 (0.92) AVACO1 allele 5(0.58), AVMIX02 allele 3(0.90), AVAG06 allele 3 (0.51) and AVAG10 allele 1 (0.62). Allele 3 at AVAG07 was common to most of the West Indian accessions, 58 accessions were homozygous for this allele, six were heterozygous leaving only one accession not having this allele. This allele also occurred in the Guatemalan and Mexican populations but at lower frequencies, 0.34 and 0.28 , respectively. Allele 3 at AVMIX02 also occurred in a high frequency with 36 accessions homozygous, 18 heterozygous and 11 not containing this allele. The frequency of this allele was low in the Guatemalan population (0.07) and moderate in the Mexican (0.20).

\section{Discussion}

Attributes that make microsatellites desirable as molecular markers include their hypervariablity, abundance and automated experimental procedures for detection. By using an automated high throughput $\mathrm{CE}$ system, we were able to analyze a large number of individuals for 14 microsatellite loci. The pattern of the PCR products produced by amplification of the genomic DNA was usually simple. It was possible to distinguish the full size amplification products containing the microsatellite from the stutter products and from the + A product. High levels of microsatellite polymorphism have been attributed to two molecular mechanisms, replication slippage and unequal crossing over (Johnson et al., 1992; Messier et al., 1996). Eleven of the 14 microsatellite loci had 15 or more alleles in this study and loci AVAG21, AVAG13, and AVAG10 could be considered hypervariable with 30,29 , and 30 alleles

Table 5. Genetic variation within the three horticultural races and among hybrid populations across 14 microsatellite loci; No.= sample size; $\mathrm{P}_{0.95}$ $=$ proportion of polymorphic loci when most frequent allele does not exceed 95\%; $\mathrm{A}=$ mean number of alleles per locus; $\mathrm{H}_{\mathrm{nb}}=$ unbiased gene diversity (Nei, 1978); $\mathrm{H}_{\mathrm{obs}}=$ observed heterozygosity. Standard deviations are indicated in parentheses.

\begin{tabular}{|c|c|c|c|c|c|}
\hline Population & No. & $\mathrm{P}_{0.95}$ & $\mathrm{~A}$ & $\mathrm{H}_{\mathrm{nb}}$ & $\overline{\mathrm{H}_{\mathrm{obs}}}$ \\
\hline Guatemalan & 35 & 1.0 & 11.29 & $0.806(0.110)$ & $0.746(0.136)$ \\
\hline West Indian & 65 & 1.0 & 11.14 & $0.607(0.226)$ & $0.496(0.242)$ \\
\hline $\mathrm{G} \times \mathrm{M}^{\mathrm{y}}$ & 30 & 1.0 & 9.86 & $0.792(0.062)$ & $0.702(0.174)$ \\
\hline$M \times W^{x}$ & 08 & 1.0 & 6.00 & $0.788(0.090)$ & $0.866(0.115)$ \\
\hline Complex hybrids & 30 & 1.0 & 8.79 & $0.752(0.109)$ & $0.779(0.144)$ \\
\hline
\end{tabular}

zListed in germplasm records at Guatemalan $\mathrm{x}$ West Indian Hybrids.

yListed as Guatemalan $x$ Mexican hybrids.

${ }^{x}$ Listed as Mexican $\mathrm{x}$ West Indian hybrids. 
detected, respectively (Table 2). When the entire 264 accessions were considered as a single population only 41 of the 256 alleles had a frequency $>0.10$. Only one allele had a frequency $>0.50$ and this was at locus AVAG07. High levels of polymorphism have been reported in other plant species. Saghai Maroof et al. (1994) detected 28 and 37 alleles at loci HVM3 and HVM4, respectively, in barley (Hordeum vulgare) and Dow et al. (1995) found high levels of polymorphism with the number of alleles at each locus ranging from 11 to 20 in wild populations of bur oak (Quercus macrocarpa).

The initial classification of the accessions by racial or hybrid group was based on the USDA records maintained at the NGRMiami and on the national germplasm database system, GRIN. Six of the West Indian accessions, 12 of the Guatemalan, and five of the Mexican accessions were of questionable characterization based on the molecular data. Estragole is a compound known to be produced in the Mexican race and in interracial hybrids involving Mexican parents. The compound imparts an anise-like scent in the leaves and the skin of the fruit (King and Knight, 1987). As a verification of the molecular data, the four accessions, two listed as West Indian and two listed as Guatemalan, that clustered with the Mexican group were found to contain estragole in the leaves. The accession 'Key Largo' was classified as Guatemalan but clustered at the interface of the Mexican and West Indian accessions and also contained estragole in its leaves. In contrast, the accession 'P.I.C. 9615' clustered within the Mexican accessions, yet the leaves do not contain estragole. It was classified as being of the Guatemalan race when collected and this classification was not changed (Ben-Ya'acov, 1995)

Most of the differences between fragment sizes found in the comparison of 'Ettinger' and 'Pinkerton' in this study versus that of Sharon et al. (1997) can be attributed to the increased sensitivity of the CE procedure as opposed to the use of polyacrylamide gels. Using $\mathrm{CE}$ we can detect differences of a single base pair in length for microsatellite fragments and the size calling is based on an internal standard placed into each sample, again giving increased confidence in accuracy of the size determination. The inability to generate amplification products for 'Pinkerton' with primers for locus AVAC01 indicates the existence of a null allele for this accession, suggesting that it is genetically different from the 'Pinkerton' accession studied by Sharon et al. (1997). We consistently detected much larger amplification products at AVAG10 (149 to 234) than were detected by Sharon et al. (1997). We are currently sequencing the alleles from AVAG10 to determine if we are amplifying the same dinucleotide repeat. Further differences between fragment sizes found in the comparison of 'Ettinger' and 'Pinkerton' in this study versus that of Sharon et al. (1997) are being investigated for other loci as well. Additionally under investigation is the basis of the existence of alleles that do not differ in size by either two bases or multiples of two bases for dinucleotide repeat microsatellites.

The Mexican, West Indian, and Guatemalan races did contain many unique alleles; however, they were all at low frequency and were not useful for predicting the horticultural race. This is in contrast to the RAPD analysis where race-specific markers were identified (Fiedler et al., 1998) and the VNTR analysis using DNA fingerprinting reported by Mhameed et al. (1997). In both of those studies a relatively small number of individuals were examined, 16 accessions in the RAPD study and 24 accessions in the VNTR study. We examined 254 accessions and did not find any useful race-specific markers and while many unique alleles did exist, the low frequency restricted their usefulness as race-specific markers.
The West Indian race does contain alleles at two loci that have frequencies greater than 90\%, AVAGG07 allele 3 and AVMIX02 allele 3 . The absence of both of these alleles in an accession would indicate that the accession is not in the West Indian race.

Mhameed et al. (1996) found high levels of $\mathrm{H}_{\mathrm{obs}}, 98 \%$, among avocado cultivars using VNTR; however using microsatellite markers the $\mathrm{H}_{\text {obs }}$ was found to be $62 \%$. In this study, the average $\mathrm{H}_{\mathrm{obs}}$ for the Guatemalan, Mexican, and West Indian races was 0.64 or very similar to the observations of Mhameed et al. (1996). In their study overall $\mathrm{H}_{\mathrm{nb}}$ was 0.56 which is lower than that found in this study where the average $\mathrm{H}_{\mathrm{nb}}$ was 0.75 for the Guatemalan, Mexican, and West Indian races. $\mathrm{H}_{\mathrm{nb}}$ was highest in Mexican and Guatemalan races and considerably lower in the West Indian race. The results indicate that avocado accessions of Mexican and Guatemalan races are highly heterozygous and heterogenous while those of the West Indian race are more homozygous and homogenous (Table 5). Davis et al. (1998) concluded that the West Indian and Guatemalan races were more similar to each other than either is to the Mexican race based on RFLP data. Our data suggest that each of the races is distinct and based on the Chi-square analysis significantly different from one another for all of the 14 loci surveyed. This is similar to the analysis by Fiedler et al. (1998) using RAPDs where the similarities delimited three groups of equal rank.

The selection of PRR-tolerant rootstocks has been reported and the tolerance has been identified in progeny of the West Indian race (Zilberstaine et al., 1995). Fourteen of the accessions evaluated in this study have been found to impart tolerance to PRR based on screening of maternal half-sib families (Ploetz et al., 2002). No obvious relationship became apparent within the PCA as they are scattered throughout the West Indian cluster and hence it is not likely that any of these microsatellites are associated with PRR resistance. $\mathrm{H}_{\mathrm{nb}}$ was low among the West Indian population (0.61) indicating that this collection of accessions is less diverse than the Guatemalan or Mexican accessions. Since PRR is such an important problem in avocado production areas, an increased sampling effort among the West Indian types is warranted. We are currently developing a project with the Centro Agronómico Tropical de Investigación y Enseñanza (CATIE) in Costa Rica to collect new West Indian accessions in selected areas of Central America.

The results presented in this study demonstrate a basic agreement between the horticultural race and the phylogenetic clusters originating from the molecular analyses. The use of the molecular data has allowed a more informed classification of avocado germplasm and will allow genetic verification of newly propagated accessions when adding them to the germplasm collection. The accessions that have been designated as possible errors or difficult to classify racial types have been entered into the GRIN system with a notation indicating that the racial designations of these accessions may need modification. Further phenotypic evaluation of the avocado germplasm collection is needed for comparison with the molecular data. This analysis demonstrates the usefulness of molecular data in the management of plant genetic resources.

\section{Literature Cited}

Anonymous. 2001. FAOSTAT online database at $<\mathrm{http} / / \mathrm{www}$.fao.org/> Ben-Ya'acov, A. 1995. The Taxonomy of the Avocado: A proposed new classification of the Persea, Sub-Genus persea. Proc. World Avocado Congr. III. Tel Aviv, Israel. p. 3-ABT-7.

Bergh, B.O. 1969. Avocado (Persea americana Mill.), p 23-51. In: F.P. 
Ferwerda and F. Wit (eds.). Outlines of perennial crop breeding in the tropics. Misc. Paper 4 Landbouwhogeschool, Wageningen, The Netherlands.

Cavalli-Sforza, L.L. and A.W.F. Edwards. 1967. Phylogenetic analysis: Models and estimation procedures. Evolution 32:550-570.

Davenport, T.L., P. Parnitzki, S. Fricke, and M.S. Hughes. 1994. Evidence and significance of self-pollinaton of avocados in Florida. J. Amer. Soc. Hort. Sci. 119:1200-1207.

Davis, J., D. Henderson, M. Kobayashi, M.T. Clegg, and M.T. Clegg. 1998. Genealogical relationships among cultivated avocado as revealed through RFLP analysis. J. Hered. 89 (4):319-323.

Dow, B.D., M.V. Ashley, and H.F. Howe. 1995. Characterization of highly variable $(\mathrm{GA} / \mathrm{CT}) \mathrm{n}$ microsatellites in the bur oak, Quercus macrocarpa. Theor. Appl. Genet. 91:137-141.

Fiedler, J., G. Bufler, and F. Bangerth. 1998. Genetic relationships of avocado (Persea americana Mill.) using RAPD markers. Euphytica 101:249-255.

Garcia, A.V. 1975. Cytogeneic studies in the genus Persea (Lauraceae). I. Karyology of seven species. Can. J. Genet. Cytol. 17:173-180.

GENETIX, logiciel sous WindowsTM pour la génétique des populations. Laboratoire Génome et Populations, CNRS UPR 9060, Université de Montpellier II, Montpellier France.

Johnson, R.E., S.T. Henderson, T.D. Petes, S. Prakash, M. Bankman, and L. Prakash. 1992. Sacharomyces cerevisiae RAD5-encoded DNA repair protein contains DNA helicase and zinc-binding sequence motifs and affects the stability of simple repetitive sequences in the genome. Mol. Cell Biol. 12:3807-3818.

King, J.R. and R.J. Knight. 1987. Occurrence and assay of estragole in the leaves of various avocado cultivars. J. Agr. Food Chem. 35: 842-844.

Knight, R.J. 2002. History, distribution and uses, p. 1-15. In: A. Whiley, B. Schaffer, and B. Wolstenholme (eds.). The avocado, botany, production and uses. CAB Intl., New York.

Lahav, E. and U. Lavi. 2002. Genetics and classical breeding, p. 39-69. In: A. Whiley, B. Schaffer, and B. Wolstenholome (eds.). The avocado, botany, production, and uses. CAB Intl., New York.

Lavi, U., J. Hillel, A. Vainstein, E. Lahav, and D. Sharon. 1991. Application of DNA fingerprints for identification and genetic analysis of avocado. J. Amer. Soc. Hort. Sci. 116:1078-1081.

Messier, W., S.H. Li, and C.B. Stewart. 1996. The birth of microsatellites. Nature 381:483.

Mhameed, S., D. Sharon, J. Hillel, E. Lahav, D. Kaufman, and U. Lavi. 1996. Level of heterozygosity and mode of inheritance of variable number of tandem repeat loci in avocado. J. Amer. Soc. Hort. Sci. 121:778-782.

Mhameed, S., D. Sharon, D. Kaufman, E. Lahav, J. Hillel, C. Degani, and U. Lavi. 1997. Genetic relationships within avocado (Persea Americana Mill) cultivars and between Persea species. Theor. Appl. Genet. 94:279-286.

Nakasone, H.Y and R.E. Paull. 1998. Avocado, p. 76-102. In: Tropical fruits. CAB Intl., New York.

Nei, M. 1987. Molecular evolutionary genetics. Columbia Univ. Press, New York.

Ploetz, R., R.J. Schnell, and J. Haynes. 2002. Variable response of open-pollinated seedling progeny of avocado to Phytophthora root rot. Phytoparasitica 30:262-268.

Popenoe, W.F. 1920. Manual of tropical and subtropical fruits. Macmillan. New York, N.Y.

Saghai Maroof, M.A., R.M. Biyashev, G.P. Yang, Q. Zhang, and R.W. Allard. 1994. Extraordinarily polymorphic microsatellite DNA in barley: Species diversity, chromosomal location, and population dynamics. Proc. Natl. Acad. Sci. USA 91:5466-5470.

Saitou, N. and M. Nei. 1987. The neighbor-joining method: Anew method for reconstructing phylogenetic trees. Mol. Biol. Evol. 4:406-425.

SAS Institute Inc. 1999. SAS/STAT user's guide. version 8. vol 2. p. 1322. SAS Inst., Cary N.C.

Sokal, R. and F.J. Rohlf. 1998. Biometry. 3rd ed. W.H. Freeman, New York.

Schnell, R.J., R. Goenaga, and C.T. Olano. 1999. Genetic similarities among cocoyam cultivars based on randomly amplified polymorphic DNA (RAPD) analysis. Scientia Hort. 80:267-276.

Scora, R.W. and B.O. Bergh. 1992. Origin of and taxonomic relationship within the genus Persea. Proc. 2nd World Avocado Congr. 2: 505-514.

Sharon, D., P.B. Cregan, S. Mhameed, K. Kusharska, J. Hillel, E. Lahav, and U. Lavi. 1997. An integrated genetic linkage map of avocado. Theor. Appl. Genet. 95:911-921.

Weir, B.S. 1996. Intraspecific differentiation, p. 391. In: D.M .Hilis, C. Moritz, and B.K. Mable (eds.). Molecular systematics. 2nd ed. Sinauer Assoc., Inc. Sunderland, Mass.

Wright, S. 1978. Evolution and the genetics of populations. vol. 4. Variability within and among natural populations. Univ. Chicago Press, Chicago.

Zilberstaine, M.,A. Ben-Ya'acov, and I. Sela. 1995. Selection of avocado rootstocks resistant to root-rot in Israel - update report. Abstr. Book 1. Proc. World Avocado Congr. III (Tel Aviv, Israel). p. 51. 